\title{
Preparation and Evaluation Pumpkin Seed Oil-based Vitamin E Cream Formulations for Topical Application
}

\author{
Teik Siun Ong ${ }^{1}$, Chee Chin Chu', Chin Ping Tan², and Kar Lin Nyam* \\ ${ }^{1}$ Department of Food Science with Nutrition, Faculty of Applied Sciences, UCSI University, 56000 Kuala Lumpur, MALAYSIA \\ ${ }^{2}$ Department of Food Technology, Faculty of Food Science and Technology, Universiti Putra Malaysia, 43400 Serdang, Selangor, MALAYSIA
}

\begin{abstract}
Plant seed oil is often incorporated into the cream emulsions to provide multifunctional effects on the skin. In the current study, pumpkin seed oil (PSO) was used to develop a stable oil-in-water emulsion. The study aimed to optimise PSO cream formulation and determine the synergistic effect of the PSO with vitamin $E$ oil added. The physical properties, antioxidant activities and storage stability of the formulations were analysed. Besides, the synergistic effect of the best formulation was analysed based on $\alpha$-tocopherol content using ultra-high performance liquid chromatography (UHPLC). The storage stability test was assessed upon storing at $25 \pm 2{ }^{\circ} \mathrm{C}$ and $40 \pm 2{ }^{\circ} \mathrm{C}$ for 12 weeks. The best formulation (20\% PSO, vitamin $\mathrm{E}$ oil and beeswax) selected showed physically and microbiologically stable. The incorporation of vitamin $E$ oil into the formulation produced with PSO was found to be compatible, as it showed a synergistic effect in the amount of $\alpha$-tocopherol content (combination index $(\mathrm{CI})=\mathbf{0 . 9 8}$ ). Thus, PSO had shown its potency to be incorporated into the topical products with a promising potential in delivering additional properties that can nourish the skin.
\end{abstract}

Key words: pumpkin seed oil (PSO), vitamin E, emulsion, stability, antioxidants

\section{Introduction}

Nowadays, skincare and cosmetic industries are driven towards the utilization of natural ingredients in the development of eco-friendly cosmetic products. There is a rapidly expanding demand for innovative natural products to overcome consumers' consciousness about their health and safety besides the desires for owing a good and pleasant appearance. Consumers are more concerned about the ingredients involved in cosmetic formulations. In this context, plant seed oils have been widely used as alternatives for raw materials because they are renewable resources, which can be extracted from different plants ${ }^{1)}$.

Vitamin $\mathrm{E}$ or tocopherol is a significant biological antioxidant. $\alpha$-tocopherol is known to be the most biologically active isoform ${ }^{2)}$ and delivers protection to the human skin by retarding the chain reactions triggered by oxidative stress $^{3,4)}$. As a free radical scavenger, it not only combats the harmful effects of ultraviolet radiation but also contributes to a moisture barrier to the skin that decelerates the aging process in return ${ }^{1,5)}$. Due to its multifunctional effects on the skin, vitamin $\mathrm{E}$ has been receiving attention in the skincare and cosmetic market throughout the years.

An emulsion is a biphasic system consisting of dispersed and continuous phases. It is widely applied in pharmaceutical, cosmetic and personal care and food products. Pumpkin (Cucurbita pepo L.) originated from Mexico and it can be found abundantly around the world ${ }^{6)}$. Pumpkin seed oil(PSO) encompasses bioactive compounds, such as tocopherols, phytosterols and phenolic acids that exhibit significant antioxidant activities ${ }^{77}$ may be a good source of cosmetic ingredient. PSO not only contains a high amount of unsaturated fatty acid but also rich in squalene, which is commonly used as a moisturizer or emollient in cosmetic products $^{8,9)}$. According to Teh and Mah, the presence of natural vitamin $\mathrm{E}$ in plant seed oil can improve the shelflife of the products ${ }^{10}$. Thus, the rationale of this research project is to optimize vitamin $\mathrm{E}$ cream with the adding of PSO and determine the presence of synergistic effect of PSO with vitamin E. Also, the physical properties, antioxidant activities and storage stability of the formulations were analysed for 12 weeks.

\footnotetext{
*Correspondence to: Kar Lin Nyam, Department of Food Science with Nutrition, Faculty of Applied Sciences, UCSI University, 56000 Kuala Lumpur, MALAYSIA

E-mail: nyamkl@ucsiuniversity.edu.my

Accepted January 10, 2020 (received for review October 1, 2019)

Journal of Oleo Science ISSN 1345-8957 print / ISSN 1347-3352 online

http://www.jstage.jst.go.jp/browse/jos/ http://mc.manusriptcentral.com/jjocs
} 


\section{Materials and Methods}

\subsection{Materials}

Pumpkins (Cucurbita pepo L.) weighted from $3 \mathrm{~kg}$ to 5 $\mathrm{kg}$ were purchased from a local hypermarket. The seeds were washed and allowed to dry at room temperature without exposing to sunlight. The ingredients that were used in the preparation of cream formulation including beeswax, vitamin $\mathrm{E}$ oil( $\alpha$-tocopherol) and xanthan gum were purchased from Sigma Aldrich (Germany). Emulsifying wax and glycerin were purchased from Croda International PLC (United Kingdom) while $\mathrm{Cetiol}^{\circledR}$ CC was purchased from BASF Care Creation (Germany).

\subsection{Methods}

2.2.1 Extraction of pumpkin seed oil (PSO)

The extraction of PSO was conducted according to the previously published method by Cheong et al. ${ }^{11)}$. Firstly, approximately $200 \mathrm{~g}$ of the dried seeds were ground into a fine powder using a grinder(Panasonic, Japan). By using Soxhlet extractor(Favorit, Thailand)with $1 \mathrm{~L}$ of hexane, the oil was extracted at $60^{\circ} \mathrm{C}$ for 3 hours. For oil recovery, hexane was then evaporated off at $40^{\circ} \mathrm{C}$ under reduced pressure rotary evaporator(Buchi, Switzerland). The freshly extracted oil was then immediately transferred to a Schott bottle covered with aluminium foil. To suppress the oxidation reaction, the oil was flushed in with $99.9 \%$ of nitrogen gas and kept in the freezer at $-20^{\circ} \mathrm{C}$ until further used.

\subsubsection{Preparation of vitamin E cream}

Six vitamin E cream formulations (Table 1) were produced with each varying the amount of PSO, vitamin E oil and beeswax, which are 10\%,15\% and 20\%. PSO and beeswax were set at the ratio of 1:2. Emulsions without PSO were known as controls. Beeswax and emulsifying wax were melted under $80^{\circ} \mathrm{C}$ water bath followed by adding Cetiol $^{\circledR}$ CC and PSO to form the lipid phase. The aqueous phase consisted of glycerin, xanthan gum and ultrapure water were heated in $80^{\circ} \mathrm{C}$ water bath. After heating, the lipid phase was gradually added into the aqueous phase under constantly magnetic stirring to form pre-emulsion and subjected to high shear homogenization at 8,000 rpm for 3 minutes. Subsequently, the emulsion was cooled to room temperature. Once the emulsion formed a uniform appearance, vitamin $\mathrm{E}$ oil was mixed manually into the emulsion.

2.2.3 Physical properties

2.2.3.1 Viscosity

The viscosity of the samples was assessed using a rheometer (ThermoHaake, Germany) with sensor cone/plate (C20/1 $\left.{ }^{\circ} \mathrm{Ti}\right)$. Approximately $40 \mathrm{mg}$ of the sample was transferred onto the reading surface of the plate. The data were analyzed using the RheoWin 3.61 program.

2.2.3.2 $\mathrm{pH}$

Before $\mathrm{pH}$ measurement, the samples were diluted with distilled water in 1:10 dilution. After that, the $\mathrm{pH}$ value was taken.

2.2.3.3 Phase separation

Phase separation of the samples was monitored using the modified method from Cheong et $a l .{ }^{11)}$. Approximately $10 \mathrm{~g}$ of the sample was first transferred into a $15 \mathrm{~mL}$ centrifuge tube. The stability of the emulsion formulations was determined based on creaming index calculated using the formula below:

$$
\text { Creaming Index }(\%)=\frac{\mathrm{H}_{\mathrm{L}}}{\mathrm{H}_{\mathrm{E}}} \times 100 \%
$$

Where $\mathrm{H}_{\mathrm{L}}$ represents the height of the cream layer; $\mathrm{H}_{\mathrm{E}}$ is the total emulsion height.

\subsubsection{Color analysis}

Color analysis was performed using a HunterLab ColorFlex EZ colorimeter according to the method of Chew et $a l{ }^{12)}$. The total color difference $\left(\Delta E^{*}\right)$ between the samples and controls was calculated using the following equation:

$$
\Delta E_{1,2}^{*}=\left[\left(L_{2}^{*}-L_{1}^{*}\right)^{2}+\left(a_{2}^{*}-a_{1}^{*}\right)^{2}+\left(b_{2}^{*}-b_{1}^{*_{1}}\right)^{2}\right]^{1 / 2}
$$

Where $L^{*}{ }_{1}, a^{*}{ }_{1}$, and $b^{*}{ }_{1}$ are the colorimeter values for samples, whilst $L^{*}{ }_{2}, a^{*}{ }_{2}$ and $b^{*}{ }_{2}$ are the colorimeter values for control samples.

Table 1 Formulations of vitamin E cream.

\begin{tabular}{lrrrrrr}
\hline \multirow{2}{*}{ Ingredients } & \multicolumn{3}{c}{ Sample (\%) } & \multicolumn{3}{c}{ Control (\%) } \\
\cline { 2 - 7 } & \multicolumn{1}{c}{ F1 } & \multicolumn{1}{c}{ F2 } & F3 & C1 & \multicolumn{1}{c}{ C2 } & C3 \\
\hline PSO & 3.0 & 4.7 & 6.3 & - & - & - \\
Vitamin E oil & 1.0 & 1.0 & 1.0 & 1.0 & 1.0 & 1.0 \\
Beeswax & 6.0 & 9.3 & 12.7 & 9.0 & 14.0 & 19.0 \\
Cetiol $^{\circledR}$ CC & 4.5 & 4.5 & 4.5 & 4.5 & 4.5 & 4.5 \\
Emulsifying wax & 9.0 & 9.0 & 9.0 & 9.0 & 9.0 & 9.0 \\
Glycerin & 3.0 & 3.0 & 3.0 & 3.0 & 3.0 & 3.0 \\
Xanthan gum & 0.5 & 0.5 & 0.5 & 0.5 & 0.5 & 0.5 \\
Ultrapure water & 73.0 & 68.0 & 63.0 & 73.0 & 68.0 & 63.0 \\
\hline
\end{tabular}




\section{Pumpkin Seed Oil-based Vitamin E Cream Formulations}

\subsubsection{In vitro antioxidant activities}

In vitro antioxidant activities of the samples were analyzed by DPPH and ABTS radical scavenging assays modified from Lee $e t a l .{ }^{13)}$. The samples were firstly diluted by ethanol to 100 dilution factors followed by 4,000 rpm centrifugation for 30 minutes. After that, $5 \mu \mathrm{L}$ sample with 195 $\mu \mathrm{L}$ DPPH or ABTS solution were mixed in 96-well microplate. The mixture was then allowed to react at $25^{\circ} \mathrm{C}$ for 30 minutes (DPPH) or 3 minutes (ABTS) and the absorbances were measured against ethanol blank at $517 \mathrm{~nm}$ for DPPH and $734 \mathrm{~nm}$ for ABTS by using a microplate reader (FLUOstar Omega, Germany). Both radical scavenging activities of the samples were expressed as mg Trolox equivalents per g of sample (mg TE/g sample) by using standard curve of Trolox, $y=-4.0986 x+1.5341$ with $R^{2}=0.9935$ for $\mathrm{DPPH}$ and $\mathrm{y}=-1.9957 \mathrm{x}+0.6316$ with $\mathrm{R}^{2}=0.9933$ for ABTS.

\subsubsection{Storage stability test}

The storage stability test was carried out based on Mohsin et $a l .{ }^{14)}$. All the samples were stored at $25 \pm 2^{\circ} \mathrm{C}$ and $40 \pm 2^{\circ} \mathrm{C}$, respectively upon 12 weeks. In vitro antioxidant activities, microbiological stability and total color difference were evaluated for every 3 weeks.

2.2.5.1 Microbiological stability

The aerobic plate count and yeast and mold count of the samples were determined according to Rana $e t a l .{ }^{15)}$ and Hashim et al. ${ }^{16)}$, respectively. Nutrient agar for aerobic plate count and potato dextrose agar for yeast and mold count were kept at $42^{\circ} \mathrm{C}$ to $46^{\circ} \mathrm{C}$. An aliquot of $0.1 \mathrm{~mL}$ of sample was aseptically plated out into a sterile petri. The agar was poured into the petri dish followed by gently swirled to disperse the sample. The agar was then left to solidify followed by 48 hours at $37^{\circ} \mathrm{C}$ for aerobic plate count or 7 days at $30^{\circ} \mathrm{C}$ for yeast and mould count. After the incubation period, the number of colony-forming units $(\mathrm{CFU} / \mathrm{mL})$ was recorded.

2.2.6 Quantification of $\alpha$-tocopherol content

The amount of $\alpha$-tocopherol was quantified based on Chew et $a l .{ }^{17)}$ with slight modifications using the ultra-high performance liquid chromatography (UHPLC) system (PerkinElmer, United States) equipped with a diode array detector(DAD). The system was associated with a reversed phase column (Cosmosil 5PFP packed column, 5 $\mu \mathrm{m} \times 250 \mathrm{~mm} \times 4.6 \mathrm{~mm}$ ) (Nacalai Tesque, Inc., Japan). The sample was completely dissolved into isopropanol followed by 4,000 rpm centrifugation for 30 minutes. After that, the supernatant was filtered using a nylon syringe filter $(0.45$ $\mu \mathrm{m})$ into a glass vial. The $\alpha$-tocopherol content was separated according to isocratic elution of the mobile phase at a flow rate of $1 \mathrm{~mL} / \mathrm{min}$ and detected at $295 \mathrm{~nm}$. The results were expressed in $\mathrm{mg} / \mathrm{g}$ sample based on the standard curve obtained from the isopropanol solutions of $\alpha$-tocopherol with the calibration equation of, $y=4166917 x$ -91518 with $R^{2}=0.9970$.

\subsubsection{Determination of the synergistic effect of vitamin E} cream

The synergistic effect of the optimised vitamin E cream was determined according to Foucquier and Guedj ${ }^{18)}$. The synergistic effect was calculated based on $\alpha$-tocopherol content using the formula as below:

$$
\text { Combination index }(C I)=\frac{E_{A}+E_{B}}{E_{A B}}
$$

Where $\mathrm{E}_{\mathrm{AB}}$ represents $\alpha$-tocopherol content of formulation F3 with the presence of both the PSO and vitamin $\mathrm{E}$ oil; $\mathrm{E}_{\mathrm{A}}$ represents $\alpha$-tocopherol content of formulation C3 with the presence of only vitamin $\mathrm{E}$ oil; $\mathrm{E}_{\mathrm{B}}$ represents the formulation S3 with the presence of only PSO.

\subsection{Statistical analysis}

All the tests were conducted in duplicate and readings were replicated $(n=4)$. The data were analyzed using Minitab 16 for Windows. One-way ANOVA was performed, and the average values were compared based on the Tukey's multiple comparison test. The differences were considered statistically significant at $p<0.05$.

\section{Results and Discussion}

\subsection{Physical properties}

The viscosity of the samples showed variation due to different concentration of the seed oil and beeswax with the ratio of 1:2 were used, respectively (Table 2). Amongst the samples, F3 had the highest viscosity $(2824.0 \mathrm{cP})$ as a total of $20 \%$ of PSO, vitamin $\mathrm{E}$ oil and beeswax were present in the formulation. As for sample F1 and F2, their respective controls were discovered to have higher viscosities due to the presences of higher amount of beeswax. However, the control, C3 showed lower viscosity than F3. F3 consisted of high amount PSO, the presence of vegetable oil may contribute to high viscosity of the formulation ${ }^{19)}$ that beyond beeswax. High viscosity aids in retarding the undesirable effects, such as phase separation ${ }^{20)}$ and thus, the shelf life of a cream formulation can be lengthened. Sample F3 had the highest viscosity compared to F2 and F1 may pose better stability.

Table 2 illustrates that there was a significant difference $(p<0.05)$ between all the samples, but the $\mathrm{pH}$ values of samples were all compatible with the skin $\mathrm{pH}$ range and will not affect the properties of the skin. Comparatively, sample F3 had the lowest $\mathrm{pH}$ value among the samples. The presence of POS and beeswax in higher amount could affect the $\mathrm{pH}$ due to the acidic compositions of the ingredi$e^{e n t s}{ }^{21}$. For the controls, they were found to be slightly acidic due to the presence of beeswax in higher concentration. This is because beeswax is one of the acidic waxes ${ }^{21)}$.

As shown in Table 2, no signs of separation were discovered, indicating that all the formulations were physically 
T. S. Ong, C. C. Chu, C. P. Tan et al.

Table 2 Physical properties of the samples.

\begin{tabular}{|c|c|c|c|c|c|c|c|c|}
\hline \multirow[b]{2}{*}{ Sample } & \multirow{2}{*}{$\begin{array}{l}\text { Viscosity } \\
(\mathrm{cP})^{* *}\end{array}$} & \multirow[b]{2}{*}{$\mathrm{pH}$ value } & \multicolumn{2}{|c|}{ Phase separation } & \multicolumn{3}{|c|}{ Color } & \multirow[b]{2}{*}{$\Delta E^{*}$} \\
\hline & & & Observation & $\begin{array}{l}\text { Creaming } \\
\text { index }(\%)\end{array}$ & $L^{*}$ & $a^{*}$ & $b^{*}$ & \\
\hline F1 & 808.5 & $5.36 \pm 0.02^{\mathrm{a}}$ & NS & - & $83.85 \pm 0.01^{\mathrm{d}}$ & $-5.37 \pm 0.01^{\mathrm{d}}$ & $17.71 \pm 0.01^{\mathrm{c}}$ & $17.83 \pm 0.01^{\circ}$ \\
\hline $\mathrm{F} 2$ & 1755.0 & $5.30 \pm 0.01^{\mathrm{ab}}$ & NS & - & $82.23 \pm 0.01^{\mathrm{e}}$ & $-4.79 \pm 0.00^{c}$ & $20.79 \pm 0.01^{\mathrm{b}}$ & $20.76 \pm 0.00^{b}$ \\
\hline F3 & 2824.0 & $5.24 \pm 0.03^{\mathrm{b}}$ & NS & - & $81.91 \pm 0.00^{\mathrm{f}}$ & $-4.84 \pm 0.01^{\mathrm{c}}$ & $22.90 \pm 0.01^{\mathrm{a}}$ & $22.66 \pm 0.01^{\mathrm{a}}$ \\
\hline $\mathrm{C} 1$ & 1335.0 & $5.10 \pm 0.01^{\mathrm{c}}$ & NS & - & $88.52 \pm 0.01^{\mathrm{c}}$ & $-0.98 \pm 0.00^{\mathrm{a}}$ & $1.07 \pm 0.01^{\mathrm{f}}$ & - \\
\hline $\mathrm{C} 2$ & 2065.0 & $5.04 \pm 0.01^{\mathrm{c}}$ & NS & - & $91.28 \pm 0.00^{\mathrm{b}}$ & $-1.04 \pm 0.00^{\mathrm{ab}}$ & $2.48 \pm 0.01^{\mathrm{e}}$ & - \\
\hline $\mathrm{C} 3$ & 2563.0 & $5.01 \pm 0.04^{\mathrm{c}}$ & NS & - & $92.03 \pm 0.00^{\mathrm{a}}$ & $-1.14 \pm 0.01^{\mathrm{b}}$ & $2.96 \pm 0.00^{\mathrm{d}}$ & - \\
\hline
\end{tabular}

F1 contains 3.0\% PSO, 1.0\% vitamin E oil and 6.0\% beeswax; F2 contains 4.7\% PSO, 1.0\% vitamin E oil and 9.3\% beeswax; F3 contains $6.3 \%$ PSO, $1.0 \%$ vitamin E oil and $12.7 \%$ beeswax; $\mathrm{C} 1$ contains $1.0 \%$ vitamin $\mathrm{E}$ oil and $9.0 \%$ beeswax; $\mathrm{C} 2$ contains $1.0 \%$ vitamin $\mathrm{E}$ oil and $14.0 \%$ beeswax; C3 contains 1.0\% vitamin E oil and $19.0 \%$ beeswax.

* Data are expressed as mean \pm standard deviation. Means within the same column with different superscripts $\left({ }^{\mathrm{a}, \mathrm{b}, \mathrm{c}, \mathrm{d}, \mathrm{e}, \mathrm{f}}\right)$ are significantly different according to Tukey's test $(p<0.05)$ except for viscosity.

** Values of viscosity $(\mathrm{cP})$ of the formulations are obtained from rheogram based on the average shear rate ranging from 97.80 to $97.88 \mathrm{~s}^{-1}$ without standard deviation.

* Data are expressed as $L^{*}$, lightness, range: -100 (black) to +100 (white); $a^{*}$, redness, range: -100 (green) to +100 (red); $b^{*}$, yellowness, range: -100 (blue) to +100 (yellow); $\Delta E^{*}$, total color difference.

* Abbreviation: NS, no separation.

stable. Arshad et $a l .{ }^{22)}$ explained that the stability of the formulations was highly contributed by the application of appropriate homogenization speed during the formation of the emulsion. The application of beeswax contributed to higher viscosity of the formulation and thus, the creaming rate could be decreased.

Among all the formulations, sample F1 $(-5.37 \pm 0.01)$ was the greenest for $a^{*}$ value, whereas sample F3 $(22.90 \pm$ $0.01)$ was the yellowest for $b^{*}$ value. F3 should be the greenest of all due to the highest percentage of PSO added, but due to the addition of the ivory white beeswax with an increasing amount, the green color of the formulations was lightened progressively from sample F1 to F3. Besides, the yellow vitamin $\mathrm{E}$ oil added into all the formulations also contributed to the $b^{*}$ value. As the controls, they were found to be mildly greenish and yellowish with increasing values of $L^{*}, a^{*}$ and $b^{*}$ from $\mathrm{C} 1$ to C3. Moreover, the total color difference $\left(\Delta E^{*}\right)$ of the samples compared to the controls were statistically significant $(p<0.05)$ with the value of $17.83 \pm 0.01,20.76 \pm 0.00$ and $22.66 \pm 0.01$ for sample F1, F2 and F3, respectively. The results of $\Delta E^{*}$ indicated the amount of PSO and beeswax affected the color of the emulsion that contributed to greenish or yellowish.

\subsection{In vitro antioxidant activity}

Based on the DPPH and ABTS values (Fig. 1), the samples with PSO (F1, F2 and F3) were significantly higher $(p<0.05)$ than their respective controls. Despite that, no significant difference was observed in both the DPPH and ABTS values between the controls (C1, C2 and C3). This indicated that the presence of PSO in the formulations had eventually contributed to antioxidant activities.

Among all the samples, F3 exerted the highest and significant DPPH radical scavenging activity with $17.14 \pm 0.05$ mg TE/g sample pertaining to its higher lipid phase concentration with respect to PSO, followed by F2 (16.62 \pm $0.10 \mathrm{mg} \mathrm{TE} / \mathrm{g}$ sample) and F1 (15.63 $\pm 0.02 \mathrm{mg} \mathrm{TE} / \mathrm{g}$ sample). A similar result was observed in the ABTS radical scavenging activity with sample F3 exhibited the highest antioxidant activity significantly with the value of $18.97 \pm$ $0.07 \mathrm{mg} \mathrm{TE} / \mathrm{g}$ sample. On the other hand, sample F1 and F2 did not show any significant antioxidant activity with $17.49 \pm 0.04 \mathrm{mg} \mathrm{TE} / \mathrm{g}$ sample and $17.72 \pm 0.21 \mathrm{mg} \mathrm{TE} / \mathrm{g}$ sample, respectively. Interestingly, the results showed that the ABTS values were slightly higher compared to the DPPH values. This was highly related to the ability of ABTS radicals in determining antioxidants with both hydrophilic and lipophilic properties ${ }^{23)}$. In relation to this, Lee et al. ${ }^{13)}$ explained that other antioxidant components besides phenolics and tocopherols might have inhibited the ABTS radicals.

\subsection{Storage stability test}

\subsubsection{In vitro antioxidant activities}

Tables $3(\mathbf{a})$ and $\mathbf{3}(\mathbf{b})$ show the results of DPPH and ABTS radical scavenging activities of formulations for 12 weeks, respectively. Upon the storage time, both the DPPH and ABTS values of samples F1, F2 and F3 decreased as a function of time and temperature. In other words, the timetemperature factor had possessed significant effects on antioxidant activities. At room temperature, the bioactive components of the samples would still be able to degrade 


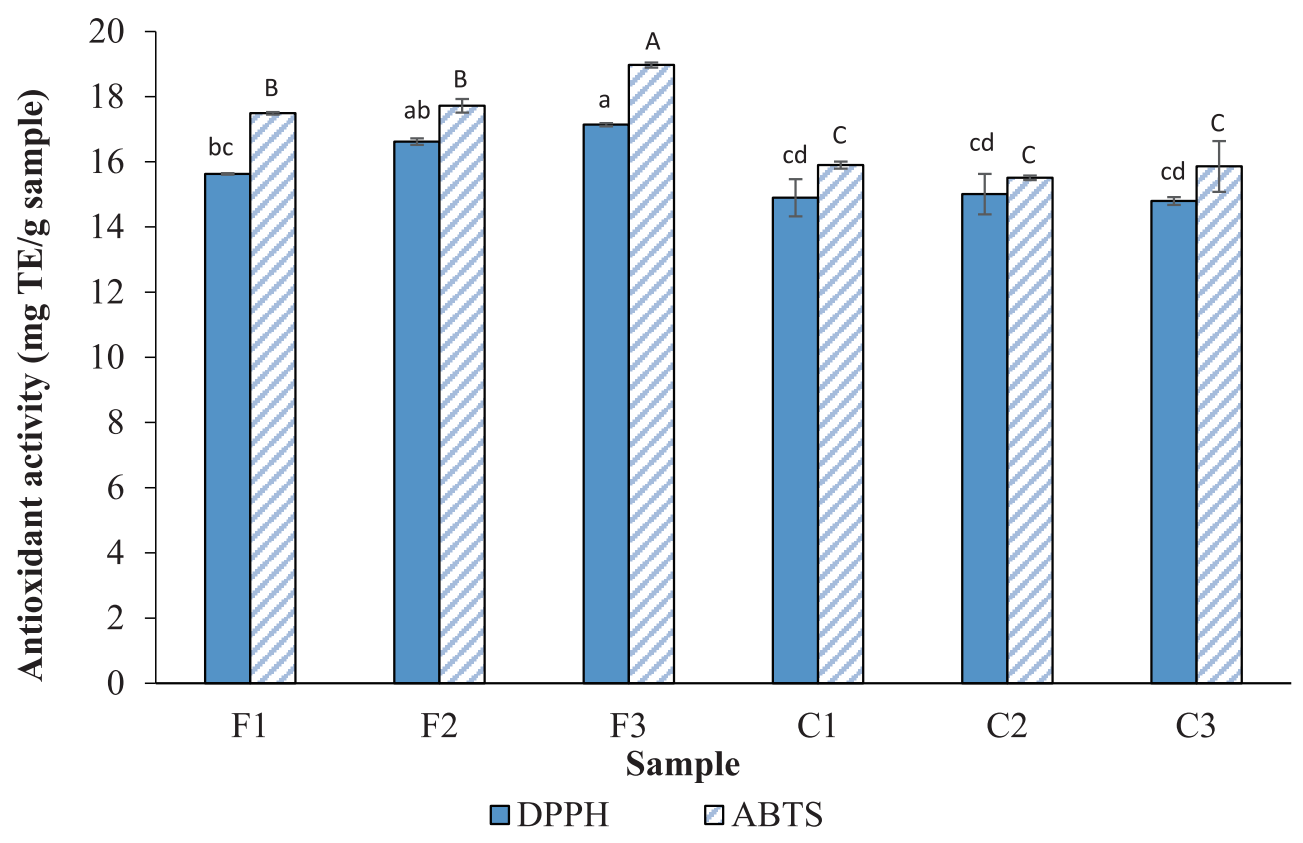

Fig. 1 DPPH and ABTS radical scavenging activity of samples.

F1 contains 3.0\% PSO, 1.0\% vitamin $\mathrm{E}$ oil and $6.0 \%$ beeswax; F2 contains 4.7\% PSO, 1.0\% vitamin $\mathrm{E}$ oil and 9.3\% beeswax; F3 contains 6.3\% PSO, 1.0\% vitamin $\mathrm{E}$ oil and 12.7\% beeswax; $\mathrm{C} 1$ contains 1.0\% vitamin $\mathrm{E}$ oil and $9.0 \%$ beeswax; C2 contains 1.0\% vitamin E oil and 14.0\% beeswax; C3 contains 1.0\% vitamin E oil and 19.0\% beeswax. * Data are expressed as mean \pm standard deviation with different superscripts $\left.{ }^{(\mathrm{a}, \mathrm{b}, \mathrm{c}, \mathrm{d}}\right)$ for DPPH and $\left.{ }^{\mathrm{A}, \mathrm{B}, \mathrm{C}, \mathrm{D}, \mathrm{D}}\right)$ for ABTS indicate significant differences from each other according to Tukey's test $(p<0.05)$.

* Abbreviations: ABTS, 2,2'-Azino-bis (3-ethylbenzothiazoline-6-sulphonic acid); DPPH, 2,2-Diphenyl-1picrylhydrazyl radical scavenging assay; TE, Trolox equivalents.

Table 3(a) DPPH radical scavenging activity of samples over storage time (mg TE/g sample).

\begin{tabular}{|c|c|c|c|c|c|c|}
\hline \multirow{2}{*}{ Sample } & \multirow{2}{*}{$\begin{array}{c}\text { Storage } \\
\text { temperature }\left({ }^{\circ} \mathrm{C}\right)\end{array}$} & \multicolumn{5}{|c|}{ DPPH (mg TE/g sample) } \\
\hline & & Week 0 & Week 3 & Week 6 & Week 9 & Week 12 \\
\hline \multirow[t]{2}{*}{ F1 } & $25 \pm 2$ & $15.63 \pm 0.02^{\mathrm{aA}}$ & $15.40 \pm 0.00^{\mathrm{ab}}$ & $15.04 \pm 0.09^{\mathrm{ab}}$ & $14.85 \pm 0.09^{\mathrm{b}}$ & $14.86 \pm 0.31^{\mathrm{b}}$ \\
\hline & $40 \pm 2$ & & $15.00 \pm 0.12^{\mathrm{A}}$ & $14.54 \pm 0.00^{\mathrm{B}}$ & $14.64 \pm 0.14^{\mathrm{B}}$ & $14.52 \pm 0.00^{\mathrm{B}}$ \\
\hline \multirow[t]{2}{*}{$\mathrm{F} 2$} & $25 \pm 2$ & $16.62 \pm 0.10^{\mathrm{aA}}$ & $15.58 \pm 0.22^{\mathrm{b}}$ & $15.11 \pm 0.04^{\mathrm{b}}$ & $15.06 \pm 0.07^{\mathrm{b}}$ & $15.02 \pm 0.19^{b}$ \\
\hline & $40 \pm 2$ & & $15.12 \pm 0.02^{\mathrm{B}}$ & $15.08 \pm 0.07^{\mathrm{B}}$ & $15.14 \pm 0.19^{\mathrm{B}}$ & $14.78 \pm 0.22^{\mathrm{B}}$ \\
\hline \multirow[t]{2}{*}{ F3 } & $25 \pm 2$ & $17.14 \pm 0.05^{\mathrm{aA}}$ & $16.31 \pm 0.22^{\mathrm{b}}$ & $15.54 \pm 0.04^{\mathrm{c}}$ & $15.25 \pm 0.07^{\mathrm{c}}$ & $15.20 \pm 0.10^{\mathrm{c}}$ \\
\hline & $40 \pm 2$ & & $15.15 \pm 0.14^{\mathrm{B}}$ & $15.34 \pm 0.05^{\mathrm{B}}$ & $15.42 \pm 0.00^{\mathrm{B}}$ & $15.33 \pm 0.17^{\mathrm{B}}$ \\
\hline \multirow[t]{2}{*}{$\mathrm{C} 1$} & $25 \pm 2$ & $14.90 \pm 0.57^{\mathrm{aA}}$ & $14.22 \pm 0.02^{\mathrm{a}}$ & $14.40 \pm 0.17^{\mathrm{a}}$ & $14.52 \pm 0.04^{\mathrm{a}}$ & $14.61 \pm 0.05^{\mathrm{a}}$ \\
\hline & $40 \pm 2$ & & $14.34 \pm 0.05^{\mathrm{A}}$ & $14.85 \pm 0.12^{\mathrm{A}}$ & $14.84 \pm 0.14^{\mathrm{A}}$ & $14.69 \pm 0.14^{\mathrm{A}}$ \\
\hline \multirow[t]{2}{*}{$\mathrm{C} 2$} & $25 \pm 2$ & $15.01 \pm 0.62^{\mathrm{aA}}$ & $14.37 \pm 0.10^{\mathrm{a}}$ & $14.35 \pm 0.04^{\mathrm{a}}$ & $14.62 \pm 0.07^{\mathrm{a}}$ & $14.75 \pm 0.16^{\mathrm{a}}$ \\
\hline & $40 \pm 2$ & & $14.57 \pm 0.21^{\mathrm{A}}$ & $14.86 \pm 0.10^{\mathrm{A}}$ & $14.85 \pm 0.16^{\mathrm{A}}$ & $14.80 \pm 0.12^{\mathrm{A}}$ \\
\hline \multirow[t]{2}{*}{$\mathrm{C} 3$} & $25 \pm 2$ & $14.80 \pm 0.12^{\mathrm{aA}}$ & $14.59 \pm 0.17^{\mathrm{a}}$ & $14.41 \pm 0.12^{\mathrm{a}}$ & $14.50 \pm 0.14^{\mathrm{a}}$ & $14.63 \pm 0.02^{\mathrm{a}}$ \\
\hline & $40 \pm 2$ & & $15.19 \pm 0.09^{\mathrm{A}}$ & $14.93 \pm 0.52^{\mathrm{A}}$ & $14.63 \pm 0.29^{\mathrm{A}}$ & $14.65 \pm 0.05^{\mathrm{A}}$ \\
\hline
\end{tabular}

F1 contains 3.0\% PSO, 1.0\% vitamin E oil and 6.0\% beeswax; F2 contains 4.7\% PSO, 1.0\% vitamin E oil and 9.3\% beeswax; F3 contains $6.3 \%$ PSO, $1.0 \%$ vitamin $\mathrm{E}$ oil and $12.7 \%$ beeswax; $\mathrm{C} 1$ contains $1.0 \%$ vitamin $\mathrm{E}$ oil and $9.0 \%$ beeswax; $\mathrm{C} 2$ contains $1.0 \%$ vitamin $\mathrm{E}$ oil and $14.0 \%$ beeswax; $\mathrm{C} 3$ contains $1.0 \%$ vitamin $\mathrm{E}$ oil and $19.0 \%$ beeswax.

* Data are expressed as mean \pm standard deviation. Means within the same row with different superscripts $\left({ }^{\mathrm{a}, \mathrm{b}, \mathrm{c}}\right)$ for $25 \pm 2^{\circ} \mathrm{C}$ and $\left({ }^{\mathrm{A}, \mathrm{B}}\right)$ for $40 \pm 2^{\circ} \mathrm{C}$ are significantly different according to Tukey's test $(p<0.05)$.

*Abbreviations: DPPH, 2,2-Diphenyl-1-picrylhydrazyl radical scavenging assay; TE, Trolox equivalents. 
T. S. Ong, C. C. Chu, C. P. Tan et al.

Table 3(b) ABTS radical scavenging activity of samples over storage time (mg TE/g sample).

\begin{tabular}{|c|c|c|c|c|c|c|}
\hline \multirow{2}{*}{ Sample } & \multirow{2}{*}{$\begin{array}{c}\text { Storage } \\
\text { temperature }\left({ }^{\circ} \mathrm{C}\right)\end{array}$} & \multicolumn{5}{|c|}{ ABTS (mg TE/g sample) } \\
\hline & & Week 0 & Week 3 & Week 6 & Week 9 & Week 12 \\
\hline \multirow[t]{2}{*}{ F1 } & $25 \pm 2$ & $17.49 \pm 0.04^{\mathrm{aA}}$ & $17.09 \pm 0.32^{\mathrm{a}}$ & $17.54 \pm 0.11^{\mathrm{a}}$ & $17.19 \pm 0.18^{\mathrm{a}}$ & $17.67 \pm 0.21^{\mathrm{a}}$ \\
\hline & $40 \pm 2$ & & $16.89 \pm 0.04^{\mathrm{AB}}$ & $16.24 \pm 0.39^{\mathrm{BC}}$ & $16.22 \pm 0.14^{\mathrm{BC}}$ & $15.86 \pm 0.21^{\mathrm{C}}$ \\
\hline \multirow[t]{2}{*}{$\mathrm{F} 2$} & $25 \pm 2$ & $17.72 \pm 0.21^{\mathrm{aA}}$ & $17.64 \pm 0.11^{\mathrm{a}}$ & $17.49 \pm 0.25^{\mathrm{a}}$ & $17.54 \pm 0.04^{\mathrm{a}}$ & $17.62 \pm 0.07^{\mathrm{a}}$ \\
\hline & $40 \pm 2$ & & $17.09 \pm 0.25^{\mathrm{AB}}$ & $16.54 \pm 0.18^{\mathrm{BC}}$ & $15.84 \pm 0.11^{\mathrm{C}}$ & $16.12 \pm 0.43^{\mathrm{BC}}$ \\
\hline \multirow[t]{2}{*}{ F3 } & $25 \pm 2$ & $18.97 \pm 0.07^{\mathrm{aA}}$ & $18.32 \pm 0.35^{\mathrm{ab}}$ & $18.07 \pm 0.35^{\mathrm{ab}}$ & $17.92 \pm 0.07^{\mathrm{b}}$ & $17.99 \pm 0.11^{\mathrm{b}}$ \\
\hline & $40 \pm 2$ & & $17.57 \pm 0.14^{\mathrm{B}}$ & $17.42 \pm 0.14^{\mathrm{B}}$ & $17.17 \pm 0.07^{\mathrm{B}}$ & $17.17 \pm 0.21^{\mathrm{B}}$ \\
\hline \multirow[t]{2}{*}{$\mathrm{C} 1$} & $25 \pm 2$ & $15.90 \pm 0.11^{\mathrm{bAB}}$ & $15.92 \pm 0.28^{\mathrm{b}}$ & $15.81 \pm 0.21^{\mathrm{b}}$ & $17.02 \pm 0.07^{\mathrm{a}}$ & $16.44 \pm 0.04^{\mathrm{ab}}$ \\
\hline & $40 \pm 2$ & & $16.32 \pm 0.85^{\mathrm{AB}}$ & $16.77 \pm 0.21^{\mathrm{AB}}$ & $17.52 \pm 0.00^{\mathrm{A}}$ & $16.67 \pm 0.21^{\mathrm{B}}$ \\
\hline \multirow[t]{2}{*}{$\mathrm{C} 2$} & $25 \pm 2$ & $15.51 \pm 0.07^{\mathrm{bA}}$ & $15.81 \pm 0.07^{\mathrm{b}}$ & $16.87 \pm 0.21^{\mathrm{a}}$ & $16.77 \pm 0.21^{\mathrm{a}}$ & $16.74 \pm 0.11^{\mathrm{a}}$ \\
\hline & $40 \pm 2$ & & $16.07 \pm 1.06^{\mathrm{A}}$ & $18.04 \pm 0.18^{\mathrm{A}}$ & $17.09 \pm 0.18^{\mathrm{A}}$ & $16.77 \pm 0.43^{\mathrm{A}}$ \\
\hline \multirow[t]{2}{*}{$\mathrm{C} 3$} & $25 \pm 2$ & $15.86 \pm 0.78^{\mathrm{aA}}$ & $15.91 \pm 0.28^{\mathrm{a}}$ & $15.86 \pm 0.14^{\mathrm{a}}$ & $16.82 \pm 0.43^{\mathrm{a}}$ & $16.49 \pm 0.04^{\mathrm{a}}$ \\
\hline & $40 \pm 2$ & & $15.76 \pm 0.50^{\mathrm{A}}$ & $17.27 \pm 0.35^{\mathrm{A}}$ & $16.54 \pm 0.11^{\mathrm{A}}$ & $16.22 \pm 0.35^{\mathrm{A}}$ \\
\hline
\end{tabular}

F1 contains 3.0\% PSO, 1.0\% vitamin E oil and 6.0\% beeswax; F2 contains 4.7\% PSO, 1.0\% vitamin E oil and 9.3\% beeswax; F3 contains $6.3 \% \mathrm{PSO}, 1.0 \%$ vitamin $\mathrm{E}$ oil and $12.7 \%$ beeswax; $\mathrm{C} 1$ contains $1.0 \%$ vitamin $\mathrm{E}$ oil and $9.0 \%$ beeswax; $\mathrm{C} 2$ contains $1.0 \%$ vitamin $\mathrm{E}$ oil and $14.0 \%$ beeswax; $\mathrm{C} 3$ contains $1.0 \%$ vitamin $\mathrm{E}$ oil and $19.0 \%$ beeswax.

* Data are expressed as mean \pm standard deviation. Means within the same row with different superscripts ${ }^{\mathrm{a}, \mathrm{b}}$ ) for $25 \pm 2{ }^{\circ} \mathrm{C}$ and $\left({ }^{\mathrm{A}, \mathrm{B}, \mathrm{C}}\right)$ for $40 \pm 2^{\circ} \mathrm{C}$ are significantly different according to Tukey's test $(p<0.05)$.

* Abbreviations: ABTS, 2,2'-Azino-bis (3-ethylbenzothiazoline-6-sulphonic acid); TE, Trolox equivalents.

due to the oxidation and polymerization reactions initiated with exposure of oxyge ${ }^{18}$. Whereas at elevated temperatures, the disintegration of bioactive compounds would happen at faster rates. Still, sample F3 exhibited the highest antioxidant activities in both tests upon the study period.

No significant difference was observed between the controls C1, C2 and C3 related to their respective storage temperatures in their DPPH values. Contrary wise, all the controls illustrated unstable antioxidant activity at both storage temperatures in ABTS radical scavenging activity. However, there was an obvious increment of antioxidant activity of the controls stored at $40 \pm 2^{\circ} \mathrm{C}$ compared to $25 \pm$ $2^{\circ} \mathrm{C}$ in both tests.

3.3.2 Microbiological stability

The findings shown in Table 3(c) revealed that all the formulations showed excellent microbiological stability, therefore contributing to a safe and stable emulsion delivery system. In relation to this, both the estimated aerobic count and yeast and mold count for all the formulations including the controls analyzed were less than $1000 \mathrm{CFU} / \mathrm{mL}$, which complied with the ASEAN microbiological limit test ${ }^{24)}$. Interestingly, the presence of vitamin $\mathrm{E}$ might have acted as a preservative to eliminate the occurrence of lipid oxidation and avoid the growth of microorganisms in cosmetic product ${ }^{25}$. Also, the cream formulations with remarkable antioxidant activity had been proven to inhibit the microbial proliferation on skin surfaces ${ }^{26)}$. Ingredients like palm-based surfactants and fatty acids might also have played a role as natural antibacterial agents ${ }^{16)}$. Apart from that, the incorporation of beeswax into the cream formulations might have highly inhibited the microbial growth ${ }^{27,28)}$.

For aerobic plate count, sample $\mathrm{F} 1$ stored at $25 \pm 2^{\circ} \mathrm{C}$ was found to be contaminated throughout the study. Guidelines of Good Manufacturing Practice(GMP) should be practiced to minimize the risks of contamination. Both the sample F2 and F3 showed minor microbial growth in aerobic plate count only on Week 3 . In this case, it might be due to the samples or equipment that had been contaminated while conducting the test. As for yeast and mold count, no colony was detected in all the plates. The optimum temperature for the growth of most of the bacteria is $37^{\circ} \mathrm{C}^{16)}$, whereas the optimum temperature for the growth of common saprophytic yeast and mould fall in the range between 20 to $30^{\circ} \mathrm{C}$. In other words, all the microorganisms are susceptible to death at any temperatures beyond their optimum temperatures. Thus, the estimated aerobic count and yeast and mold count for the formulations were all less than $100 \mathrm{CFU} / \mathrm{mL}$ at the storage temperature of $40 \pm 2^{\circ} \mathrm{C}$.

3.3.3 Total color difference

Table 3 $(\mathrm{d})$ shows significant $(p<0.05)$ differences in the total color difference $\left(\Delta E^{*}\right)$ upon 12 weeks of storage. The results showed that all the values exceeded 3 and thus, obvious color changes could be observed among the samples. As mentioned previously, the $\Delta E^{*}$ value was di- 
Table 3(c) Estimated aerobic plate count and estimated yeast and mould count of formulations over storage time (CFU/ $\mathrm{mL}$ ).

\begin{tabular}{cccccccccc}
\hline \multirow{2}{*}{ Sample } & $\begin{array}{c}\text { Storage } \\
\text { temperature }\left({ }^{\circ} \mathrm{C}\right)\end{array}$ & \multicolumn{3}{c}{ Estimated aerobic plate count $(\mathrm{CFU} / \mathrm{mL})$} & \multicolumn{3}{c}{ Estimated yeast and mould count $(\mathrm{CFU} / \mathrm{mL})$} \\
\cline { 2 - 8 } & Week 3 & Week 6 & Week 9 & Week 12 & Week 3 & Week 6 & Week 9 & Week 12 \\
\hline F1 & $25 \pm 2$ & 150 & 200 & 200 & 150 & $<100$ & $<100$ & $<100$ & $<100$ \\
& $40 \pm 2$ & $<100$ & $<100$ & $<100$ & $<100$ & $<100$ & $<100$ & $<100$ & $<100$ \\
F2 & $25 \pm 2$ & 150 & $<100$ & $<100$ & $<100$ & $<100$ & $<100$ & $<100$ & $<100$ \\
& $40 \pm 2$ & $<100$ & $<100$ & $<100$ & $<100$ & $<100$ & $<100$ & $<100$ & $<100$ \\
F3 & $25 \pm 2$ & 150 & $<100$ & $<100$ & $<100$ & $<100$ & $<100$ & $<100$ & $<100$ \\
& $40 \pm 2$ & $<100$ & $<100$ & $<100$ & $<100$ & $<100$ & $<100$ & $<100$ & $<100$ \\
C1 & $25 \pm 2$ & $<100$ & $<100$ & $<100$ & $<100$ & $<100$ & $<100$ & $<100$ & $<100$ \\
& $40 \pm 2$ & $<100$ & $<100$ & $<100$ & $<100$ & $<100$ & $<100$ & $<100$ & $<100$ \\
C2 & $25 \pm 2$ & $<100$ & $<100$ & $<100$ & $<100$ & $<100$ & $<100$ & $<100$ & $<100$ \\
& $40 \pm 2$ & $<100$ & $<100$ & $<100$ & $<100$ & $<100$ & $<100$ & $<100$ & $<100$ \\
C3 & $25 \pm 2$ & $<100$ & $<100$ & $<100$ & $<100$ & $<100$ & $<100$ & $<100$ & $<100$ \\
& $40 \pm 2$ & $<100$ & $<100$ & $<100$ & $<100$ & $<100$ & $<100$ & $<100$ & $<100$ \\
\hline
\end{tabular}

F1 contains 3.0\% PSO, 1.0\% vitamin E oil and 6.0\% beeswax; F2 contains 4.7\% PSO, 1.0\% vitamin E oil and 9.3\% beeswax; F3 contains $6.3 \% \mathrm{PSO}, 1.0 \%$ vitamin $\mathrm{E}$ oil and $12.7 \%$ beeswax; $\mathrm{C} 1$ contains $1.0 \%$ vitamin $\mathrm{E}$ oil and $9.0 \%$ beeswax; $\mathrm{C} 2$ contains $1.0 \%$ vitamin $\mathrm{E}$ oil and $14.0 \%$ beeswax; $\mathrm{C} 3$ contains $1.0 \%$ vitamin $\mathrm{E}$ oil and $19.0 \%$ beeswax.

* Abbreviation: CFU, colony-forming unit.

Table 3(d) Total color difference of samples over storage time.

\begin{tabular}{cccccc}
\hline \multirow{2}{*}{ Sample } & $\begin{array}{c}\text { Storage } \\
\text { temperature }\left({ }^{\circ} \mathrm{C}\right)\end{array}$ & \multicolumn{3}{c}{ Total color difference $\left(\Delta E^{*}\right)$ from Week 0 } \\
\cline { 2 - 6 } & $25 \pm 2$ & $0.25 \pm 0.02^{\mathrm{C}}$ & $1.01 \pm 0.02^{\mathrm{b}}$ & $1.35 \pm 0.02^{\mathrm{a}}$ & $1.01 \pm 0.01^{\mathrm{b}}$ \\
$\mathrm{F} 1$ & $40 \pm 2$ & $1.12 \pm 0.00^{\mathrm{D}}$ & $3.00 \pm 0.01^{\mathrm{A}}$ & $2.83 \pm 0.02^{\mathrm{B}}$ & $1.45 \pm 0.01^{\mathrm{C}}$ \\
& $25 \pm 2$ & $0.41 \pm 0.02^{\mathrm{a}}$ & $0.52 \pm 0.03^{\mathrm{a}}$ & $0.51 \pm 0.08^{\mathrm{a}}$ & $0.48 \pm 0.00^{\mathrm{a}}$ \\
$\mathrm{F} 2$ & $40 \pm 2$ & $2.00 \pm 0.04^{\mathrm{B}}$ & $1.91 \pm 0.06^{\mathrm{B}}$ & $1.90 \pm 0.06^{\mathrm{B}}$ & $2.56 \pm 0.07^{\mathrm{A}}$ \\
& $25 \pm 2$ & $1.15 \pm 0.01^{\mathrm{a}}$ & $1.14 \pm 0.02^{\mathrm{a}}$ & $0.64 \pm 0.01^{\mathrm{b}}$ & $0.59 \pm 0.00^{\mathrm{C}}$ \\
$\mathrm{F} 3$ & $40 \pm 2$ & $1.54 \pm 0.01^{\mathrm{C}}$ & $1.58 \pm 0.02^{\mathrm{C}}$ & $2.35 \pm 0.00^{\mathrm{B}}$ & $2.49 \pm 0.01^{\mathrm{A}}$ \\
& $25 \pm 2$ & $0.46 \pm 0.03^{\mathrm{d}}$ & $1.68 \pm 0.03^{\mathrm{b}}$ & $2.60 \pm 0.00^{\mathrm{a}}$ & $0.56 \pm 0.02^{\mathrm{C}}$ \\
$\mathrm{C} 1$ & $40 \pm 2$ & $2.62 \pm 0.02^{\mathrm{B}}$ & $3.27 \pm 0.02^{\mathrm{A}}$ & $3.29 \pm 0.01^{\mathrm{A}}$ & $1.45 \pm 0.00^{\mathrm{C}}$ \\
& $25 \pm 2$ & $0.94 \pm 0.01^{\mathrm{b}}$ & $0.73 \pm 0.01^{\mathrm{C}}$ & $0.65 \pm 0.01^{\mathrm{d}}$ & $1.39 \pm 0.01^{\mathrm{a}}$ \\
$\mathrm{C} 2$ & $40 \pm 2$ & $3.78 \pm 0.01^{\mathrm{A}}$ & $2.21 \pm 0.01^{\mathrm{C}}$ & $3.78 \pm 0.01^{\mathrm{A}}$ & $3.09 \pm 0.00^{\mathrm{B}}$ \\
& $25 \pm 2$ & $0.24 \pm 0.00^{\mathrm{d}}$ & $1.99 \pm 0.01^{\mathrm{a}}$ & $1.74 \pm 0.02^{\mathrm{b}}$ & $1.53 \pm 0.01^{\mathrm{C}}$ \\
$\mathrm{C} 3$ & $40 \pm 2$ & $3.18 \pm 0.02^{\mathrm{C}}$ & $2.45 \pm 0.00^{\mathrm{D}}$ & $3.33 \pm 0.01^{\mathrm{B}}$ & $3.92 \pm 0.01^{\mathrm{A}}$ \\
\hline
\end{tabular}

F1 contains 3.0\% PSO, 1.0\% vitamin E oil and 6.0\% beeswax; F2 contains $4.7 \% \mathrm{PSO}, 1.0 \%$ vitamin $\mathrm{E}$ oil and $9.3 \%$ beeswax; $\mathrm{F} 3$ contains $6.3 \% \mathrm{PSO}, 1.0 \%$ vitamin $\mathrm{E}$ oil and $12.7 \%$ beeswax; $\mathrm{C} 1$ contains $1.0 \%$ vitamin $\mathrm{E}$ oil and $9.0 \%$ beeswax; $\mathrm{C} 2$ contains $1.0 \%$ vitamin $\mathrm{E}$ oil and $14.0 \%$ beeswax; $\mathrm{C} 3$ contains $1.0 \%$ vitamin $\mathrm{E}$ oil and $19.0 \%$ beeswax.

* Data are expressed as mean \pm standard deviation. Means within the same row with different superscripts $\left({ }^{\mathrm{a}, \mathrm{b}, \mathrm{c}, \mathrm{d}}\right.$ ) for $25 \pm 2^{\circ} \mathrm{C}$ and $\left({ }^{\mathrm{A}, \mathrm{B}, \mathrm{C}, \mathrm{D}}\right)$ for $40 \pm 2^{\circ} \mathrm{C}$ are significantly different according to Tukey's test $(p<0.05)$.

rectly related to the increase of PSO concentration in the formulations. As for Table 3(d), the values of $\Delta E^{*}$ of all the formulations at the storage temperature of $25 \pm 2^{\circ} \mathrm{C}$ upon the entire study period were less than 1.5 except for control $\mathrm{C} 1$ and $\mathrm{C} 3$, which fell in the range between 1.5 to 3. Hence, they did not display any remarkable alterations in their colors. Hydrolysis of the fatty acid esters to free fatty acids in the cream emulsions would be highly favored at el- 
Table 4 Synergistic effect of the best formulation calculated based on the quantity of $\alpha$-tocopherol content identified ( $\mathrm{mg} / \mathrm{g}$ sample).

\begin{tabular}{ccc}
\hline Sample & $\alpha$-tocopherol $(\mathrm{mg} / \mathrm{g}$ sample $)$ & Combination index $(\mathrm{CI})$ \\
\hline F3 & $11.26 \pm 0.25^{\mathrm{a}}$ & $0.98^{*}$ \\
C3 & $10.78 \pm 0.60^{\mathrm{a}}$ & \\
S3 & $0.22 \pm 0.00^{\mathrm{b}}$ & \\
\hline
\end{tabular}

F3 contains $6.3 \%$ PSO, $1.0 \%$ vitamin E oil and $12.7 \%$ beeswax; C3 contains $1.0 \%$ vitamin $\mathrm{E}$ oil and $19.0 \%$ beeswax; S3 contains $7.3 \%$ PSO and $12.7 \%$ beeswax.

* Data are expressed as mean \pm standard deviation. Means within the column with different superscripts $\left({ }^{(a, b}\right)$ are significantly different according to Tukey's test $(p<0.05)$.

${ }^{*} \mathrm{CI}<1$ indicates synergism; ${ }^{* *} \mathrm{CI}=1$ indicates additive effect; $* * * \mathrm{CI}>1$ indicates antagonism.

evated temperatures ${ }^{29)}$. Eventually, both the free fatty acids and color compound might stimulate oxidation and cause unpleasant color and odor in the final products ${ }^{12}$.

At $40 \pm 2^{\circ} \mathrm{C}$, the $\Delta E^{*}$ values of all the samples shown were not stable with time. As it was seen, the minor color difference indicated that longer storage periods with increased temperature can only alter the color slightly ${ }^{30}$. On the other hand, the variation of the color may be triggered by the deterioration of active components due to the growth of microorganisms during the storage time ${ }^{22,31)}$. Since the values were still less than 3 , the color changes of the samples could not be perceived easily. Conversely, all the 3 controls had the $\Delta E^{*}$ values more than 3 .

\subsection{Determination of synergistic effect of vitamin E cream}

3.4.1 Identification and quantification of tocopherol content

The combination index (CI) of response additivity approach is a standard measure in the indication of synergism $(\mathrm{CI}<1)$, antagonism $(\mathrm{CI}>1)$ or additive $\operatorname{effect}(\mathrm{CI}=1)$ in drug combinations ${ }^{18)}$. Among the samples, sample F3 was selected as the best formulation as it was the most stable sample with the best properties throughout the analysis conducted. From Table 4, the CI revealed was 0.98, which indicated that there was a synergistic effect with the presence of PSO and vitamin $\mathrm{E}$ oil in sample F3.

Based on the results shown in Table 4, the $\alpha$-tocopherol content of F3 with both PSO and vitamin E oil showed $11.26 \pm 0.25 \mathrm{mg} / \mathrm{g}$ sample, $\mathrm{S} 3$ without vitamin $\mathrm{E}$ oil showed only $0.22 \pm 0.00 \mathrm{mg} / \mathrm{g}$ sample whereas C3 without PSO showed $10.78 \pm 0.60 \mathrm{mg} / \mathrm{g}$ sample. Thus, the combination of both the PSO and vitamin E oil in sample F3 had successfully given rise to the $\alpha$-tocopherol content with respect to its antioxidant properties. From the results for in vitro antioxidant activity, it also displayed the highest value in both the DPPH and ABTS radical scavenging activities among all the formulations shown in Fig. 1. This indicated that the incorporation of PSO and vitamin $\mathrm{E}$ oil into the formulation provides potential protective activity, which contributes to scavenging free radicals and decreasing both acute and chronic skin responses. In other words, the antioxidant activity performed by sample F3 had shown its suitability to be applied in skincare products.

\section{Conclusion}

Pumpkin seed oil-based vitamin E cream exhibited good emulsion stability with no phase separation and creaming observed. The emulsion formulation optimised during the study was F3. F3 with 20\% PSO, vitamin E oil and beeswax was chosen as the best formulation because it exhibited to be stable upon 12 weeks storage period. Besides being physically and antioxidative stable, it also showed microbial stability, which was considered safe to be used. The incorporation of the active agent, vitamin $\mathrm{E}$ oil with PSO showed synergistic effect $(\mathrm{CI}=0.98)$, that can increase the amount of $\alpha$-tocopherol content. In turn, the $\alpha$-tocopherol enhanced the antioxidant activities of F3 as shown in the $\operatorname{DPPH}(17.14 \pm 0.05 \mathrm{mg} \mathrm{TE} / \mathrm{g}$ sample) and ABTS $(18.97 \pm$ $0.07 \mathrm{mg} \mathrm{TE} / \mathrm{g}$ sample). In conclusion, PSO may be a potential source to be included in personal care and cosmetic industries.

\section{Acknowledgment}

Financial support of this work by the Ministry of Higher Education through the Fundamental Research Grant Scheme (FRGS/1/2018/WAB01/UCSI/02/1) is gratefully acknowledged.

\section{References}

1) Pinto, F.; de Barros, D.P.C.; Fonseca, L.P. Design of 


\section{Pumpkin Seed Oil-based Vitamin E Cream Formulations}

multifunctional nanostructured lipid carriers enriched with $\alpha$-tocopherol using vegetable oils. Ind. Crops Prod. 118, 149-159(2018).

2) Montenegro, L. Nanocarriers for skin delivery of cosmetic antioxidants. J. Pharm Pharmacogn. Res. 2, 73-92 (2014).

3) Sarangarajan, R.; Meera, S.; Rukkumani, R.; Sankar, P.; Anuradha, G. Antioxidants: Friend or Foe? Asian Pac. J. Trop. Med. 10, 1111-1116(2017).

4) Ribeiro, A.S.; Estanqueiro, M.; Oliveira, M.B.; Sousa Lobo, J.M. Main benefits and applicability of plant extracts in skin care products. Cosmetics 2, 48-65 (2015).

5) Muthukumarasamy, R.; Ideris, N. Formulation and evaluation of antioxidant cream containing methanolic extract of piper betel leaves. Int. J. Pharm. Bio. Sci. 7, 323-328 (2016).

6) Hancock, J. Plant evolution and the origin of crop species. CABI Publishing, Wallingford (2014).

7) Nyam, K.L.; Tan, C.P.; Lai, O.M.; Long, K.; Che Man, Y. Physicochemical properties and bioactive compounds of selected seed oils. LWT-Food Sci. Tech. 42, 13961403 (2009).

8) Sethi, A.; Kaur, T.; Malhotra, S.K.; Gambhir, M.L. Moisturizers: The slippery road. Indian J. Dermatol. 61, 279-287 (2016).

9) Bardaa, S.; Ben Halima, N.B.; Aloui, F.; Ben Mansour, R.B.; Jabeur, H.; Bouaziz, M.; Sahnoun, Z. Oil from pumpkin (Cucurbita pepo L.) seeds: Evaluation of its functional poperties on wound healing in rats. Lipids Health Dis. 15, 1-12 (2016).

10) Teh, S.S; Mah, S.H. Stability evaluations of different types of vegetable oil-based emulsions. J. Oleo Sci. 67, 1381-1387 (2018).

11) Cheong, A.M.; Tan, K.W.; Tan, C.P.; Nyam, K.L. Kenaf (Hibiscus cannabinus L.) seed oil-in-water pickering nanoemulsions stabilised by mixture of sodium caseinate, Tween 20 and $\beta$-cyclodextrin. Food Hydrocoll. 52, 934-941 (2016).

12) Chew, S.C.; Tan, C.P.; Long, K.; Nyam, K.L. Effect of chemical refining on the quality of kenaf (Hibiscus cannabinus) seed oil. Ind. Crop. Prod. 89, 59-65 (2016).

13) Lee, X.Y.; Chu, C.C.; Azizul Hasan, Z.A.; Chua, S.K.; Nyam, K.L. Novel nanostructured lipid carriers with photoprotective properties made from carnauba wax, beeswax, and kenaf seed oil. J. Am. Oil Chem. Soc. 96, 201-211 (2019).

14） Mohsin, S.; Akhtar, N.; Mahmood, T.; Khan, H.; Mustafa, R. Formulation and stability of topical water in oil emulsion containing corn silk extract. Trop. J. Pharm. Res. 15, 1115-1121 (2016).

15) Rana, J.; Sultana, T.; Das, K.K.; Noor, R. Microbiological analysis of topicals available in Bangladesh. Int. J.
Pharm. Pharm. Sci. 6, 330-332(2014).

16) Hashim, S. A survey on cosmetic products marketed in Malaysia: Microbiological aspect. Oil Palm Bulletin 47, 37-48 (2003).

17) Chew, S.C.; Tan, C.P.; Nyam, K.L. Application of response surface methodology for optimizing the deodorization parameters in chemical refining of kenaf seed oil. Sep. Puri. Tech. 184, 144-151(2017).

18) Foucquier, J.; Guedj, M. Analysis of drug combinations: Current methodological landscape. Pharmacol. Res. Perspect. 3, e00149 (2015).

19) Saket K.; Aarti, T.; Nitesh K.; Maen M. H. A novel oilin-water drilling mud formulated with extracts from Indian mango seed oil. Pet. Sci. 1, 1-15(2019).

20) Censi, R.; Peregrina, D.P.; Lacava, G.; Agas., D.; Lupidi, G.; Sabbieti, M.G.; Martino, P.D. Cosmetic formulation based on an Açai extract. Cosmetics 5, 48 (2018).

21) Acton, A. Citrates - Advances in research and application 2013 edition. ScholarlyEditions, Atlanta (2013).

22) Arshad, A.I.; Haji, M.S.; Akhtar, N. Fabrication, preliminary stability evaluation and in-vitro characterization of polysiloxane polyalkyl polyether copolymer-based cosmetic emulsion. Latin Am. J. Pharm. 34, 17971807 (2015).

23) Ratz-Lyko, A.; Arct, J.; Pytkowska, K. Methods for evaluation of cosmetic antioxidant capacity. Skin Res. Tech. 18, 421-430 (2012).

24) ASEAN Guidelines on Limits of Contaminants for Cosmetic[Internet]. ASEAN. https://www.hsa.gov.sg/content/dam/HSA/HPRG/Cosmetic_Products/ASEAN\% 20Guidelines \% 20on \%20Limits \% 20of\%20Contaminants\%20for\%20Cosmetics.pdf. Accessed 30 July 2019.

25) Kerdudo, A.; Burger, P.; Merck, F.; Dingas, A.; Rolland, Y.; Michel, T.; Fernandez, X. Development of a natural ingredient - Natural preservative: A case study. C. $R$. Chimie 19, 1077-1089 (2016).

26) Singh, M.; Seth, P.; Poddar, S. Comparative analysis of four facial foundation lotions with reference to its antioxidant richness and bio-safety. Cosmetics 4, 12 (2017).

27) Cornara, L.; Biagi, M.; Xiao, J.; Burlando, B. Therapeutic properties of bioactive compounds from different honeybee products. Front. Pharmacol. 8, 412 (2017).

28) Fratini, F.; Cilia, G.; Turchi, B.; Felicioli, A. Beeswax: A minireview of its antimicrobial activity and its application in medicine. Asian Pac. J. Trop. Med. 9, 839-843 (2016).

29) Altuntaş, E.; Yener, G. Anti-aging potential of a cream containing herbal oils and honey: Formulation and in vivo evaluation of effectiveness using non-invasive biophysical techniques. IOSR J. Pharm. Bio. Sci. 10, 2319-7676 (2015). 
T. S. Ong, C. C. Chu, C. P. Tan et al.

30) Angkatavanich, J.; Dahlan, W.; Nimmannit, U.; Sriprasert, V.; Sulongkood, N. Development of clay liquid detergent for Islamic cleansing and the stability study. Int. J. Cosmet. Sci. 31, 131-141 (2009).

31) Waqas, M.K.; Akhtar, N.; Ahmad, M.; Murtaza, G.;
Khan, H.M.; Iqbal, M.; Rasul, A.; Bhatti, N.S. Formulation and characterization of a cream containing extract of fenugreek seeds. Acta Poloniae Pharma. 67, 173-178(2010). 